УДК 517.1

\title{
Impact of Transverse Magnetic Field Thermal Radiation on Non-darcy Forced Convection Flow
}

\author{
Nilangshu Acharya* \\ P.R. Thakur Govt. College \\ Gaighata, W.B., Pin-743287 \\ India \\ Subrata Jana ${ }^{\dagger}$ \\ Prafullanagar Vidyamandir (H.S) \\ Habra, 24Pgs(N), W. B., Pin:743268 \\ India \\ Kalidas Das D $^{\ddagger}$ \\ A.B.N.Seal College \\ Cooch Behar, W.B., Pin-736101
}

India

Received 25.04.2017, received in revised form 15.06.2017, accepted 06.09.2017

This work investigates the influence of transverse magnetic field on forced convective flow and heat transfer of an incompressible electrically conducting fluid past a semi-infinite porous plate embedded in a Darcy-Forchheimer porous medium. Thermal radiation and viscous dissipation are considered in energy equation. The resulting mathematical model of the differential equations are converted into a set of coupled non-linear ordinary differential equations by using similarity transformations and then solved numerically by employing fourth order RK-method with shooting technique. The local skin friction coefficient and Nusselt number are computed, graphical results for the dimensionless velocity and temperature field are reported and examined for some pertinent parameters showing the interacting aspects of the obtained solution.

Keywords: forced convective flow, porous medium, thermal radiation, magnetic field, viscous dissipation. DOI: 10.17516/1997-1397-2018-11-1-18-29.

\section{Introduction and preliminaries}

Convective flow in a porous media is widely studied in the recent years due to its wide applications in engineering as post-accidental heat removal in nuclear reactors, underground disposal of nuclear waste, solar collectors, drying processes, heat exchangers, geothermal and petroleum reservoir operations, building construction. Cheng and Minkowycz [1] presented similarity solutions for free convective heat transfer from a vertical plate in a fluid-saturated porous medium. The heat and mass transfer by mixed convection from a vertical plate in a saturated porous medium was analyzed by Lai and Kulacki [2]. Wu et al. [3] presented a non-linear exact and asymptotic solutions to Navier Stokes equation of Brinkman type on a problem of stagnation point flows in a porous medium. The Darcy model, which states that the volume averaged velocity is proportional to the pressure gradient, is shown to be valid under the conditions of low velocities and small porosity (Hong et al. [4]). But the Darcy law is not suitable in many

\footnotetext{
*nilangshu.math@gmail.com

†jana05subrata@gmail.com

${ }^{\ddagger} \mathrm{kd} \_$kgec@rediffmail.com

(C) Siberian Federal University. All rights reserved
} 
practical situations, the porous medium bounded by an impermeable wall, higher flow rates and non-uniform porosity distribution in the near wall region. Therefore, it is necessary to include the non-Darcian terms in the analysis of the convective transport in a porous medium. The inertia effect is expected to be important at higher flow rate and it can be accounted for through the addition of a velocity-squared term in the momentum equation, which is known as the Forchheimer extension. The effects of flow inertia on vertical, natural convection in saturated porous medium were investigated by Chen and Ho [5]. Chen et al. [6] discussed the effects of non-Darcian mixed convection about a vertical cylinder in a porous medium. The effects of non-Darcian surface tension on free surface transport in porous medium were studied by Chen and Vafai [7]. Aziz [8] and Ishak [9] studied the similarity solutions for flow and heat transfer characteristics with convective boundary condition under different geometrical configurations. Sheikholeslami and Chamkha [10] considered an interesting problem on Electrohydrodynamic free convection heat transfer of a nanofluid in a semi-annulus enclosure with a sinusoidal wall. Some others problems $[11,12]$ on entropy generation with Lattice Boltzmann method of solution have been discussed by Sheikholeslami and co-researchers.

The effect of radiation on flow and heat transfer problem has become more important industrially. At high operating temperature, radiation effect can be quite significant. Many process in engineering areas occur at high temperature and a knowledge of radiation heat transfer becomes very important for design of reliable equipment, nuclear plants, gas turbines and various propulsion devices or aircraft, missiles, satellites and space vehicles. Based on these applications, Cogley et al. [13] showed that in the optically thin limit, the fluid does not absorb its own emitted radiation but the fluid does absorb radiation emitted by the boundaries. Raptis [14] investigated the steady flow of a viscous fluid through a porous medium bounded by a porous plate subject to a constant suction velocity in presence of thermal radiation. Makinde [15] examined the transient free convection interaction with thermal radiation of an absorbing emitting fluid along moving vertical permeable plate. Raptis and Perdikis [16] discussed viscoelastic flow in the presence of radiation. Mukhopadhyay et al. [17] analyzed heat transfer over a porous plate in a DarcyForchheimer porous medium in presence of radiation. In recent year, Hsiao [18] studied combined electrical MHD Ohmic dissipation forced and free convection of an incompressible Maxwell fluid.

The study of magnetic field effects on the flow and heat transfer in an electrically conducting fluid permeated by a transverse magnetic field is of special interest and has many practical applications in physics and engineering. In Study of magnetohydrodynamics, electromagnetic fields is use to control the heat transfer as in the convection flows and aerodynamic heating while the heating produced by electromagnetic fields is use in MHD generators, pumps, etc. There have been several studies on the effect of the magnetic field on the flow and heat transfer problems. Helmy [19] presented variable electric conductivity effect on MHD boundary layer equations for power law fluids. Seddeek and Aboeldahab [20] examined the effects of the thermal radiation on the MHD flow and heat transfer past a semi-infinite porous plate. Chamkha [21] studied the MHD flow over a permeable surface in the presence of heat generation/absorption and a chemical reaction. Ibrahim et al. [22] discussed the case of mixed convection flow of a micropolar fluid past a semi infinite, steady moving porous plate with varying suction velocity normal to the plate in presence of thermal radiation and viscous dissipation. Hayat et al. [23] studied a two dimensional mixed convection boundary layer MHD stagnation point flow through a porous medium bounded by a stretching vertical plate with thermal radiation. MHD mixed convection from a vertical plate embedded in a porous medium with a convective boundary condition was discussed by Makinde and Aziz [24]. Olajuwon [25] examined convection heat and mass transfer in a hydromagnetic flow of a second grade fluid in the presence of thermal radiation and thermal diffusion. Das [26] investigated the impact of thermal radiation on MHD slip flow over a flat plate with variable fluid properties. Kandelousi [27] presented the effect of spatially variable magnetic field on ferrofluid flow and heat transfer subject to constant heat flux boundary condition. An advanced problem on variable magnetic field with forced convection 
was done by Sheikholeslami et al. [28]. Again, Sheikholeslami and co-authors $[29,30]$ presented a numerical study of MHD free convection $\mathrm{Al}_{2} \mathrm{O}_{3}$ water nanofluid with thermal radiation effect and impact of thermal radiation on MHD flow and heat transfer by means of two phase model respectively.

In addition to a magnetic field, one has to consider the effect of viscous dissipation on the boundary layer flow because this changes the temperature distribution by playing a role like an energy source, which leads to affect heat transfer rates. The merit of the effect of viscous dissipation depends on whether the sheet is being cooled or heated. The effect of viscous dissipation in natural convection processes has been studied by Gebhart [31] and Gebhart and Mollendorf [32]. They observed that the effect of viscous dissipation is significant in vigorous natural convection and mixed convection processes. The transfer characteristics over a stretching surface with viscous dissipation in the presence of internal heat generation or absorption was studied by Vajravelu and Hadjinicolaou [33]. Jafar et al. [34] investigated the effects of MHD flow and heat transfer over a stretching/shrinking sheet with an external magnetic field, viscous and Joules dissipation. MHD slip flow and heat transfer with effects of buoyancy, viscous and Joules dissipation over a non-linear stretching porous sheet was analyzed by Abel et al. [35].

The present study has been undertaken to analyze the forced convective flow and heat transfer of an incompressible electrically conducting fluid past a semi-infinite porous plate embedded in a Darcy-Forchheimer porous medium. The effects of transverse magnetic field and viscous dissipation are included in the presence of thermal radiation. Numerical solutions of the boundary layer equations are obtained, and discussion is provided for several values of pertinent parameters governing the problem.

\section{Analysis}

Let us consider a hot vertical plate embedded in a saturated porous medium subjected to a transverse magnetic field as shown in Fig. 1. We assume that the flow is two dimensional, steady

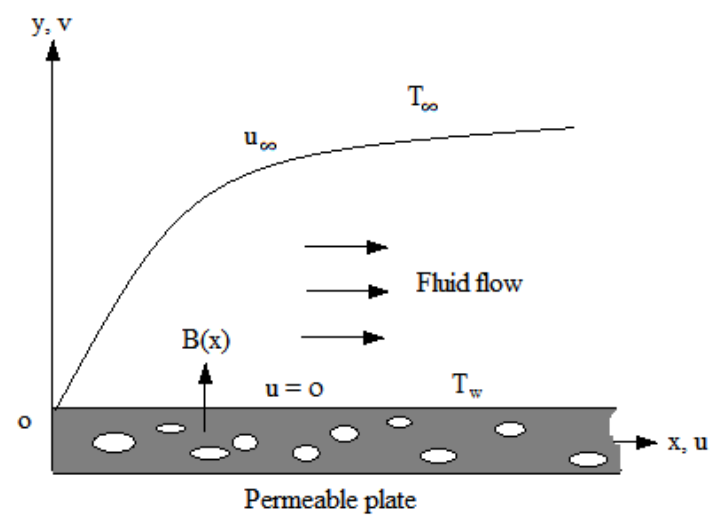

Fig. 1. Physical Model of the Problem

with forced convection past a flat plate. The governing equations is based on Darcy-Forchheimer model, which accounts for the drag (represented by Darcy term) exerted by porous media as well as the inertia effect(represented by the non linear Forchheimer term). In a Cartesian frame of reference, the mass, momentum and energy conservation equations with transverse magnetic field, thermal radiation and viscous dissipation may be expressed as

$$
\frac{\partial u}{\partial x}+\frac{\partial v}{\partial y}=0,
$$




$$
\begin{gathered}
u \frac{\partial u}{\partial x}+v \frac{\partial u}{\partial y}=\nu \frac{\partial^{2} u}{\partial y^{2}}-\frac{\nu}{k}\left(u-u_{\infty}\right)-\frac{k^{\prime}}{\sqrt{k}}\left(u^{2}-u_{\infty}^{2}\right)-\frac{\sigma B(x)^{2}}{\rho}\left(u-u_{\infty}\right), \\
u \frac{\partial T}{\partial x}+v \frac{\partial T}{\partial y}=\frac{\kappa}{\rho c_{p}} \frac{\partial^{2} T}{\partial y^{2}}-\frac{1}{\rho c_{p}} \frac{\partial q_{r}}{\partial y}+\frac{\mu}{\rho c_{p}}\left(\frac{\partial u}{\partial y}\right)^{2} .
\end{gathered}
$$

In the previous equations, $u$ and $v$ are the components of velocity respectively in the $x$ and $y$ directions, $B(x)=\frac{B_{0}}{\sqrt{x}}$ is the magnetic flux density, $\mu$ is the coefficient of fluid viscosity, $\rho$ is the fluid density, $\nu=\frac{\mu}{\rho}$ is the kinematic viscosity, $k=k_{0} x$ is the Darcy permeability of porous medium, $k_{0}$ is the initial permeability, $k^{\prime}=\frac{k_{0}^{\prime}}{\sqrt{x}}$ is the Forchheimer resistance factor, $k_{0}^{\prime}$ is the Forchheimer constant, which has been experimentally measured for different porous media. $\mathrm{T}$ is the temperature, $\kappa$ is the thermal conductivity of the fluid, $u_{\infty}$ is the free stream velocity, $T_{w}$ and $T_{\infty}$ are the wall temperature and free stream respectively with $T_{w}>T_{\infty}, q_{r}$ is the radiative heat flux and $c_{p}$ is the specific heat at constant pressure.

The radiative heat flux term $q_{r}$ by using the Rosseland approximation is given by

$$
q_{r}=-\frac{4 \sigma^{*}}{3 k^{*}} \frac{\partial T^{4}}{\partial y}
$$

where $\sigma^{*}$ is the Stefan-Boltzmann constant and $k^{*}$ is the mean absorption coefficient.

The appropriate boundary conditions are

$$
\left.\begin{array}{l}
u=0, v= \pm v_{w}(x), T=T_{w} \text { at } y=0, \\
u=u_{\infty}, T=T_{\infty} \text { as } y \rightarrow \infty,
\end{array}\right\}
$$

where suction/injection velocity $v_{w}(x)$ is given by $v_{w}(x)=\frac{v_{0}}{\sqrt{x}}$ (Mukhopadhyay et al. [17]), $v_{0}$ is the constant value of suction/injection.

\section{Similarity analysis and solution procedure}

The momentum and energy equations (2), (3) can be transformed into the corresponding nonlinear ordinary differential equations by using the following similarity transformations :

$$
\eta=y \sqrt{\frac{u_{\infty}}{\nu x}}, \psi=\sqrt{u_{\infty} \nu x} f(\eta), \theta=\frac{T-T_{\infty}}{T_{w}-T_{\infty}},
$$

where $\eta$ is the similarity variable, $f(\eta)$ is the dimensionless stream function and $\theta(\eta)$ is the dimensionless temperature. Further, $\psi$ is the stream function defined as $u=\partial \psi / \partial y$ and $v=$ $-\partial \psi / \partial x$, which identically satisfies Eq. 1.

Substituting (6) into Eqs.(2), (3) yield the following self similar equations:

$$
\begin{gathered}
f^{\prime \prime \prime}+\frac{1}{2} f f^{\prime \prime}-\left(k_{1}+M^{2}\right)\left(f^{\prime}-1\right)-k_{2}\left(f^{\prime 2}-1\right)=0, \\
\theta^{\prime \prime}\left[1+\frac{4}{3 N}\left\{1+\left(\theta_{r}-1\right) \theta\right\}^{3}\right]+\frac{4}{N}\left\{1+\left(\theta_{r}-1\right) \theta\right\}^{2}\left(\theta_{r}-1\right) \theta^{\prime 2}+\frac{P_{r}}{2} f \theta^{\prime}+\operatorname{Pr} E c f^{\prime \prime 2}=0,
\end{gathered}
$$

where $k_{1}=d \frac{\nu}{k_{0} u_{\infty}}$ is the parameter of the porous medium, $k_{2}=\frac{k_{0}^{\prime}}{\sqrt{k_{0}}}$ is the inertial parameter, $E c=\frac{u_{\infty}^{2}}{\rho c_{p}\left(T_{w}-T_{\infty}\right)}$ is the Eckert number, $M=B_{0} \sqrt{\frac{\sigma}{\mu u_{\infty}}}$ is the magnetic field parameter, 
$R e_{x}=\frac{u_{\infty} x}{\nu}$ is the local Reynolds number, $\theta_{r}=\frac{T_{w}}{T_{\infty}}$ is the temperature ratio of the medium, $N=\frac{\kappa k^{*}}{4 \sigma T_{\infty}^{3}}$ is the radiation parameter and $\operatorname{Pr}=\frac{\mu c_{p}}{\kappa}$ is the the Prandtl number. It should be noted that $k_{1}^{-1}$ and $k_{2}$ will reflect the effect of Darcian and Forchheimer flows on the present problem.

The transformed boundary conditions become:

$$
\left.\begin{array}{l}
f^{\prime}=0, f=S, \theta=1 \text { at } \eta=0, \\
f^{\prime}=1, \theta=0 \text { as } \eta \rightarrow \infty,
\end{array}\right\}
$$

where $S=\frac{-2 v_{0}}{\sqrt{u_{\infty} \nu}}$ is the suction/injection parameter.

The parameters of engineering interest in heat transfer problems are the skin friction coefficient (wall shear stress) $C_{f}$ and the local Nusselt number (rate of heat transfer) $N u$ which are important for this kind of flow. These parameters respectively characterize the surface drag and wall heat transfer rate. The equation defining the wall shear stress is given by

$$
\tau_{w}=\mu\left(\frac{\partial u}{\partial y}\right)_{y=0} .
$$

So the local skin friction coefficient on the surface can be expressed as

$$
C_{f}=\frac{\tau_{w}}{\rho u_{\infty}^{2}}=R e_{x}^{-1 / 2} f^{\prime \prime}(0) .
$$

The quantity of heat transfer through the unit area of the surface is given by

$$
q_{w}=-\kappa\left(\frac{\partial T}{\partial y}\right)_{y=0} .
$$

So the rate of heat transfer in terms of the dimensionless Nusselt number can be written as:

$$
N u=-R e_{x}^{-1 / 2} \theta^{\prime}(0) .
$$

\section{Method of solution}

The Eqs. (7), (8) can be put in a system of first order simultaneous ordinary differential equations as follows

$$
\left.\begin{array}{l}
f^{\prime}=f_{1}, \\
f_{1}^{\prime}=f_{2}, \\
\theta^{\prime}=f_{3}, \\
f_{2}^{\prime}=-\frac{1}{2} f f_{2}+\left(k_{1}+M^{2}\right)\left(f_{1}-1\right)+k_{2}\left(f_{1}^{2}-1\right), \\
f_{3}^{\prime}=\frac{-\frac{4}{N}\left\{1+\left(\theta_{r}-1\right) \theta\right\}^{2}\left(\theta_{r}-1\right) f_{3}^{2}-\frac{1}{2} \operatorname{Prff} f_{3}-\operatorname{Pr} E c f_{2}^{2}}{\left[1+\frac{4}{3 N}\left\{1+\left(\theta_{r}-1\right) \theta\right\}^{3}\right]},
\end{array}\right\}
$$

and from (9), we have following initial conditions and boundary conditions

$$
\begin{gathered}
f_{1}(0)=0, f(0)=S, \theta(0)=1, \\
f_{1}(\infty)=1, \theta(\infty)=0 .
\end{gathered}
$$


The above system of simultaneous first order ordinary differential equations (14) having five unknowns $\left[f, f_{1}, f_{2}, f_{3}, \theta\right]$ subject to the initial conditions (15) is solved numerically by employing fourth order Runge-Kutta integration scheme accompanied with the Shooting scheme. Making an initial guess for the values of $f_{2}(0)$ and $f_{3}(0)$ i.e. $f^{\prime \prime}(0)$ and $\theta^{\prime}(0)$ to initiating the shooting process is very crucial in this process. The success of the procedure depends very much on how good this guess is. Numerical solutions are obtained for several values of the physical parameters i.e. magnetic field parameter $M$, thermal radiation parameter $N r$, Eckert number $E c$, suction/injection parameter $S$ etc. We have chosen a step size of $\Delta \eta=0.01$ to satisfy the convergence criterion of $10^{-6}$ in all cases. For numerical computation infinity condition has been considered for a large but finite value of $\eta$ where no considerable variation in velocity, temperature etc. occurs.

\subsection{Verification of the results}

In order to ascertain the accuracy of our computed results, the present study (in the absence of magnetic field and viscous dissipation) is compared with the previously published work of Mukhopadhyay et.al [17]. The non-dimensional velocity profiles is shown in Fig. 2. It is observed that the results obtained here agree very well with those of Mukhopadhyay et.al [17].

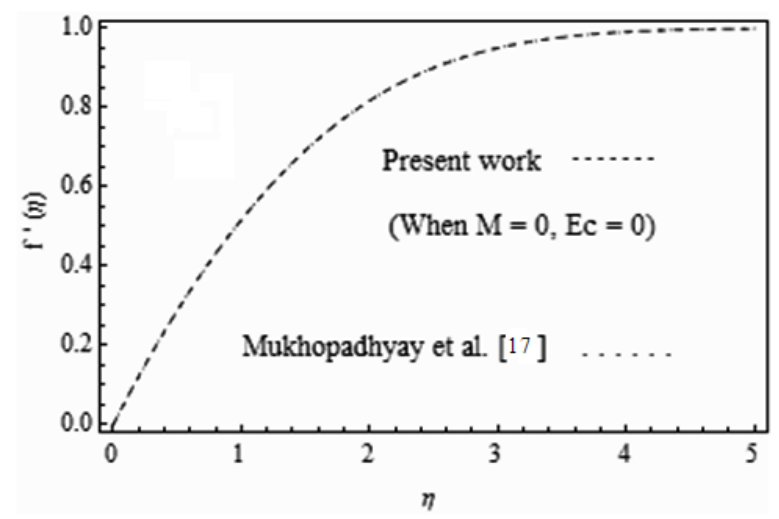

Fig. 2. Velocity distribution in absence of magnetic field and viscous dissipation

\section{Results and Discussion}

In order to gain physical insight of the present problem, the numerical results for velocity, temperature, skin friction and Nusselt number etc. have been presented graphically in Figs. 3-9 and in Tab. 1 for several sets of values of the parameters, encountered in the problem. In the simulation the default values of the parameters are considered as $M=0.4, E c=0.2, \theta_{r}=0.4$, $N=0.2, k_{1}=0.2, k_{2}=0.2, P r=0.71$ and $S=1$ unless otherwise specified.

The influences of magnetic field parameter $M$ on the velocity profile is depicted in Fig. 3 . It can be seen that increasing $M$ is to reduce the velocity distribution in the boundary layer which results in thining of the boundary layer thickness, and hence induces an increase in the value of the velocity gradient i.e. the skin friction coefficient as shown in Tab. 1. From table it is also observed that an increase in $M$ enhances the rate of heat transfer at the surface of the plate. Fig. 4 shows variations in the velocity versus $\eta$ for different values of the porosity parameter $k_{1}$. One can observed that as $k_{1}$ increases, the velocity increases in the boundary layer region. Thus the effect of increasing values of the porosity parameter is to increase the momentum boundary layer thickness. Tab. 1 shows that porosity parameter $k_{1}$ enhances the skin friction coefficient 
Table 1. Effects of various parameters on $C f$ and $N u$

\begin{tabular}{|c|c|c|c|c|c|c|c|c|}
\hline$M$ & $N$ & $E c$ & $S$ & $k_{1}$ & $k_{2}$ & $\theta_{r}$ & $C f$ & $N u$ \\
\hline 0.0 & 0.4 & 0.2 & 1.0 & 0.2 & 0.2 & 0.4 & 1.07199 & 1.89097 \\
\hline 0.2 & & & & & & & 1.09500 & 1.91286 \\
\hline 0.4 & & & & & & & 1.16088 & 1.99784 \\
\hline \multirow[t]{17}{*}{0.2} & 0.4 & & & & & & 1.09500 & 1.99286 \\
\hline & 0.8 & & & & & & - & 0.84623 \\
\hline & 1.2 & & & & & & - & 0.64128 \\
\hline & 1.6 & & & & & & - & 0.55290 \\
\hline & 0.4 & 0.0 & & & & & - & 2.20832 \\
\hline & & 0.2 & & & & & - & 1.99286 \\
\hline & & 0.4 & & & & & - & 1.79368 \\
\hline & & 0.2 & 1.0 & & & & 1.09500 & 1.99286 \\
\hline & & & 2.0 & & & & 1.46930 & 2.99900 \\
\hline & & & -1.0 & & & & 0.53167 & 0.49419 \\
\hline & & & -2.0 & & & & 0.36812 & 0.15081 \\
\hline & & & 1.0 & 0.0 & & & 0.973605 & 1.98197 \\
\hline & & & & 0.2 & & & 1.09500 & 1.99286 \\
\hline & & & & 0.4 & & & 1.20249 & 2.00068 \\
\hline & & & & 0.1 & 0.0 & & 0.848492 & 1.96695 \\
\hline & & & & & 0.2 & & 1.03636 & 1.98789 \\
\hline & & & & & 0.4 & & 1.19018 & 2.00014 \\
\hline
\end{tabular}

$C_{f}$ as well as the Nusselt number. The influence of inertial parameter $k_{2}$ over dimensionless velocity is shown in Fig. 5. Figure guarantees streamwise velocity component $f^{\prime}(\eta)$ increases with the increase of the inertial parameter $k_{2}$. Consequently, the momentum boundary layer thickness increases with the increasing values of $k_{2}$. Thus, the non-Darcian i.e. Forchheimer term has a very significant effect on the velocity distribution. Tab. 1 indicates that an increase in the inertial parameter increases the wall shear stress and the rate of heat transfer. Fig. 6 illustrates variations in the temperature $\theta$ versus similarity variable $\eta$ for different values of the thermal radiation parameter $N$. It should be noted that for lower values of $N$, the temperature increases more rapidly in comparision to higher values of $N$ and, as a consequence, thickness of the thermal boundary layer increases. It is observed from the Tab. 1 that $N$ diminishes the rate of heat transfer at the wall of the plate by almost $86.59 \%$ as thermal radiation parameter changes from 0.4 to 1.6. In Fig. 7, the effects of Eckert number $E c$ over dimensionless temperature profiles is shown graphically. It is observed that an increase of Eckert number increases the temperature within the region $\eta<2.0$ ( not precisely determined ) but outside this region the effect is not significant. The reason behind this is that the heat energy is stored in the liquid due to the frictional heating. The impact of Eckert number Ec on the skin friction and Nusselt number may be analyzed from Tab. 1. It can be noted that the effect of $E c$ is to reduce the Nusselt number but have no effect on skin friction coefficient. Figs. 8 and 9 describe respectively the behaviors of the velocity profile and temperature profile for different values of suction/injection parameter $S$. It is noticed that the effect of suction parameter $S(>0)$ accelerates the velocity whereas opposite effect occurs for injection parameter $S(<0)$ which is described in Fig. 6. An increase in suction parameter $S(>0)$ is associated with a decrease in temperature distribution which in turn diminishes the thickness of thermal boundary layer and the reverse trend is observed for injection $S(<0)$. These phenomenon is illustrated in Fig. 7. Further it is clear from Tab. 1 
that suction $(S>0)$ enhances the heat transfer coefficient much better than injection $(S<0)$. Thus, suction can be used as a means for cooling the surface much faster than injection.

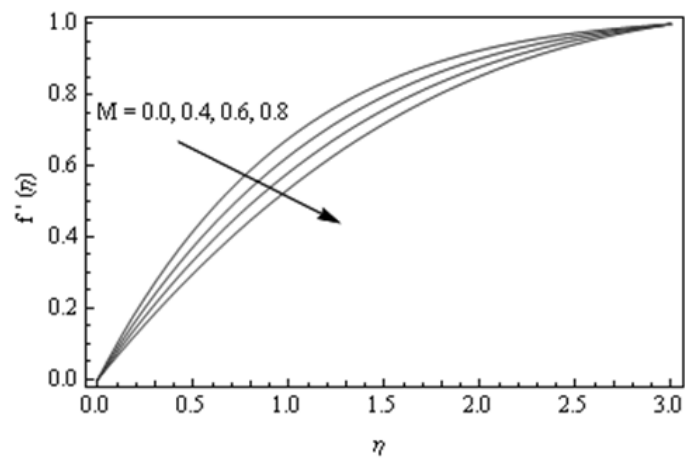

Fig. 3. Effect of magnetic field parameter $M$ on velocity distribution

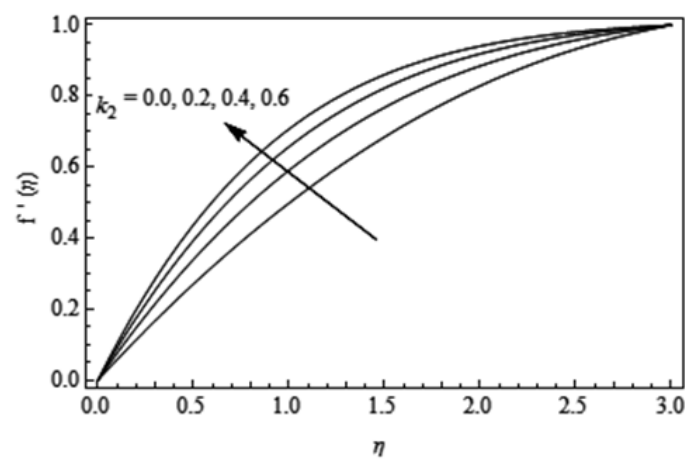

Fig. 5. Effect of inertial parameter $k_{2}$ on velocity distribution

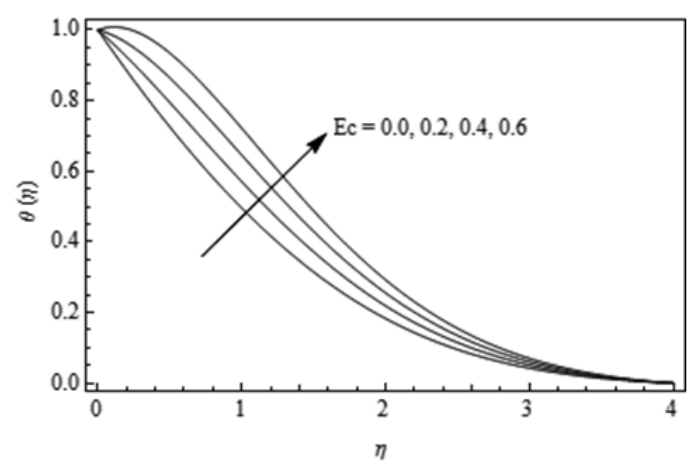

Fig. 7. Effect of Eckert number $E c$ on temperature distribution

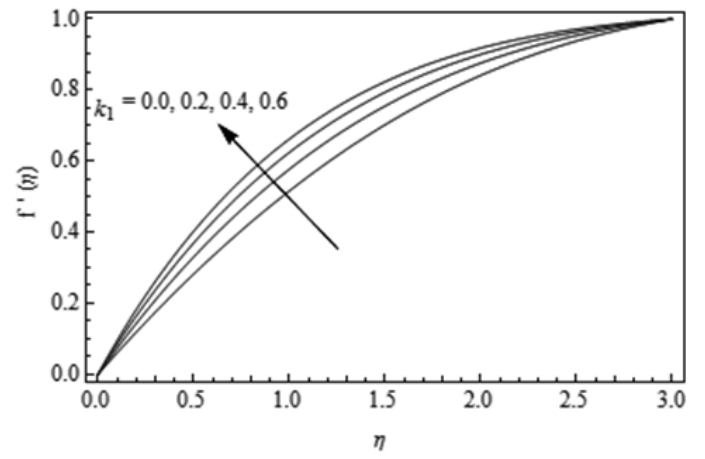

Fig. 4. Effect of permeability parameter $k_{1}$ on velocity distribution

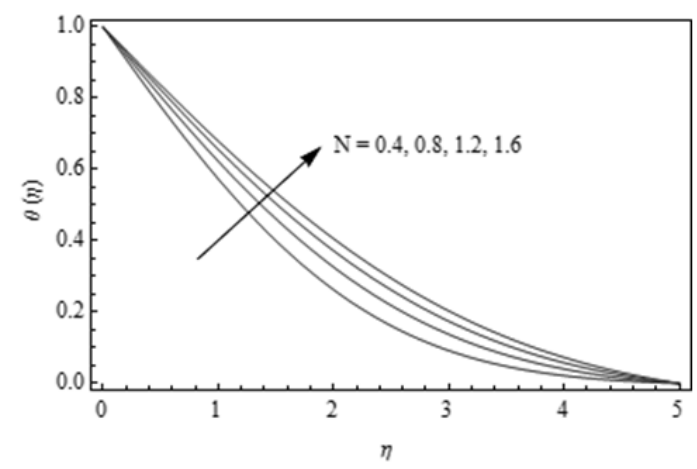

Fig. 6. Effect of thermal radiation parameter $N$ on temperature distribution

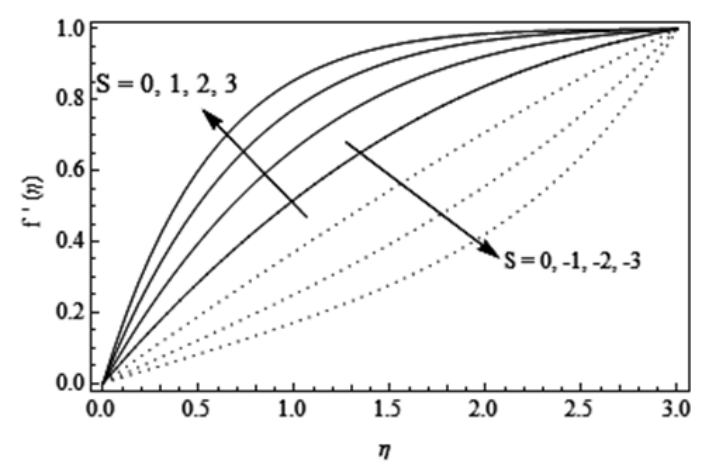

Fig. 8. Effect of suction/injection parameter $S$ on velocity distribution 


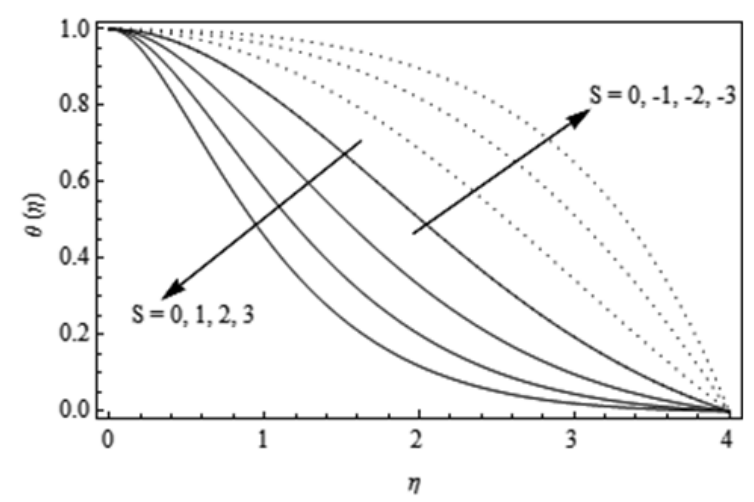

Fig. 9. Effect of suction/injection parameter $S$ on temperature distribution

\section{Concluding remarks}

The present study gives the numerical solutions for steady forced convective boundary layer flow and heat transfer of an incompressible electrically conducting fluid over a semi-infinite porous plate embedded in a Darcy-Forchheimer porous medium in presence of magnetic field, thermal radiation and viscous dissipation. With the help of similarity transformations, the governing equations are reduced to self similar non-linear ordinary differential equations which are then solved using fourth order RK-method with shooting technique. The findings of the present study are applicable in the analysis in various branches of geothermal engineering, petroleum technology and also in the metallurgical chemistry to study the heat transfer on a liquid metal. Main conclusions of the study are as follows:

- An increase in the magnetic field parameter $M$ decreases the fluid velocity, which in turn decreases the boundary layer thickness.

- An important observation of the study is that an increase in the thermal radiation parameter decreases the rate of heat transfer across the thermal boundary layer region.

- Temperature of the conducting fluid increases more rapidly for higher values of Eckert number $E c$.

- The wall mass transfer rate and the wall heat transfer rate both are increasing functions of $k_{1}$ and $k_{2}$.

- The suction/injection parameter has a great influence on the rate of heat transfer and so can be used as means of cooling.

Under some limiting conditions such as zero magnetic field effect, the current results are consistent with results available in the literature.

The authors wish to express their cordial thanks to reviewers for valuable comments to improve the presentation of the article.

\section{References}

[1] P.Cheng, W.J.Minkowycz, Free convection about a vertical flat plate embedded in a porous medium with application to heat transfer from a disk, J. Geophys Res., 82(1977), 2040-2044.

[2] L.F.Cai, F.A.Kulacki, Non-Darcy mixed convection along a vertical wall in a saturated porous medium, Int. J. Heat Mass Transf., 113(1991), 252-255. 
[3] Q.Wu, S.Weinbaum, Y.Andreopoulos, Stagnation point flows in porous medium, Chem. Eng Sci., 60(2005), 123-134.

[4] J.T.Hong, Y.Yamada, C.L.Tien, Effects of non-Darcian and non-uniform porosity on vertical plate natural convection in a porous media, Trans. ASME Jour. Heat Transfer., 109(1987), 356-362.

[5] K.S.Chen, J.R.Ho, Effects of flow inertia on vertical natural convection in saturated porous media, Int. J. Heat Mass Transf., 29(1988), 753-759.

[6] C.K.Chen, C.H.Chen, M W.J.inkowycz, U.S.Gill, Non-Darcian effects on mixed convection about a vertical cylinder embedded in a saturated porous medium, Int. J. Heat Mass Transf., 35(1992), 3041-3046.

[7] S.C.Chen, K.Vafai, Non-Darcian surface tension effects on free surface transport in porous media, Numer. Heat Transfer., Part A, bf 31(1997), 235-245.

[8] A.Aziz, A similarity solution for laminar thermal boundary layer over a flat plate with a convective surface boundary condition, Commun. Nonlinear Sci. Numer. Simul., 14(2009), 1064-1068.

[9] A.Ishak, Similarity solutions for flow and heat transfer over a permeable surface with convective boundary condition, Appl Math Comput., 217(2010), 837-842.

[10] M.Sheikholeslami, A.J.Chamkha, Electrohydrodynamic free convection heat transfer of a nanofluid in a semi-annulus enclosure with a sinusoidal wall, Num. Heat Transfer, part A, 69(2016), no. 7, 781-793

[11] M.Sheikholeslami, D.D.Ganji, Entropy generation of nanofluid in presence of magnetic field using Lattice Boltzmann Method, Physica A, 417(2015), 273-286.

[12] M.Sheikholeslami, H.R.Ashorynejad, P.Rana, Lattice Boltzmann simulation of nanofluid heat transfer enhancement and entropy generation, Journal of Molecular Liquids, 214(2016), 86-95.

[13] A.C.Cogley, W.E.Vincenty, S.E.Gilles, Differential approximation for radiation in a non-gray gas near equilibrium, AIAA Jour., 6(1968), 551-553.

[14] A.Raptis, Radiation and free convection flow through a porous medium, Int. Commun. Heat Mass Transf., 2(1998), 289-295.

[15] O.D.Makinde, Free convection flow with thermal radiation and mass transfer past a moving vertical porous plate, Int. Comm. Heat Mass Transfer, 32(2005), 1411-1419.

[16] A.Raptis, C.Perdikis, Viscoelastic flow by the presence of radiation, J. Appl. Maths and Mechs., 78(1998), 277-279.

[17] S.Mukhopadhyay, P.R.De, K.Bhattacharyya, G.C.Layek, Forced convective flow and heat transfer over a porous plate in a Darcy-Forchheimer porous medium in presence of radiation, Meccanica, 47(2012), 153-161.

[18] K.L.Hsiao, Combined Electrical MHD Heat Transfer Thermal Extrusion System Using Maxwell Fluid with Radiative and Viscous Dissipation Effects, Applied Thermal Engineering, 2016. DOI: 10.1016/j.applthermaleng.2016.08.208.

[19] K.A.Helmy, MHD boundary layer equations for power law fluids with variable electric conductivity, Meccanica, 30(1995), 187-200. 
[20] M.A.Seddeek, F.M.Aboeldahab, Radiation effects on unsteady MHD free convection with Hall current near an infinite vertical porous plate, Int. J. Maths and Mathematical sciences, 26(2001), 249-255.

[21] A.J.Chamkha, MHD flow of a uniformly stretched vertical permeable surface in the presence of heat generation/absorption and a chemical reaction, Int. Comm Heat Mass Transfer, 30(2003), 413-422.

[22] F.S.Ibrahim, A.M.Elaiw, A.A.Bakr, Influence of viscous dissipation and radiation on unsteady MHD mixed convection flow of micropolar fluids, Appl. Math. Inf. Sci., 2(2008), 143-162.

[23] T.Hayat, Z.Abbas, I.Pop, S.Asghar, Effects of radiation and magnetic field on the mixed convection stagnation-point flow over a vertical stretching sheet in a porous medium, Int. J. Heat Mass Transfer, 53( 2010), 466-474.

[24] O.D.Makinde, A.Aziz, MHD mixed convection from a vertical plate embedded in a porous medium with a convective boundary condition, Int Jour Therm Sci., 49(2010), 1813-1820.

[25] B.I.Olajuwon, Convection heat and mass transfer in a hydromagnetic flow of a second grade fluid in the presence of thermal radiation and thermal diffusion, Int. Comm. Heat Mass Trans., 38(2011), 377-382.

[26] K.Das, Impact of thermal radiation on MHD slip flow over a flat plate with variable fluid properties, Heat Mass and Transfer, 48(2012), 767-778.

[27] M.S.Kandelousi, Effect of spatially variable magnetic field on ferrofluid flow and heat transfer considering constant heat flux boundary condition, The Eur. Physical J. Plus, (2014), 129-248.

[28] M.Sheikholeslami, K.Vajravelu, M.M.Rashidi, Forced convection heat transfer in a semi annulus under the influence of a variable magnetic field, International Journal of Heat and Mass Transf., 92(2016), 339-348.

[29] M.Sheikholeslami, T.Hayat, A.Alsaedi, MHD free convection of Al2O3 ?ater nanofluid considering thermal radiation: a numerical study, Int. J. of Heat and Mass Transf., 96(2016), 513-524.

[30] M.Sheikholeslami, D.D.Ganji, M.Y.Javed, R.Ellahi, Effect of thermal radiation on magnetohydrodynamics nanofluid flow and heat transfer by means of two phase model, Journal of Magnetism and Magnetic Materials, 374(2015), 36-43.

[31] B.Gebhart, Effect of viscous dissipation in natural convection, J. Fluid Mech., 14(1962), 225-232.

[32] B.Gebhart, J.Mollendorf, Viscous dissipation in external natural convection flows, J. Fluid Mech., 38(1969), 97-107.

[33] K.Vajravelu, A.Hadjinicolaou, Heat transfer in a viscous fluid over a stretching sheet with viscous dissipation and internal heat generation, Int. Commun. Heat Mass Transfer, 20(1993), 417-430.

[34] K.Jafar, R.Nazar, A.Ishak, I.Pop, MHD Flow and Heat Transfer over stretching shrinking sheets with external magnetic field, viscous dissipation and Joule Effects, Can. J. Chem. Eng., 99(2011), 1-11. 
[35] M.S.Abel, K.A.Kumar, R.Ravikumara, MHD Flow and Heat Transfer with Effects of Buoyancy, Viscous and Joules Dissipation over a Nonlinear Vertical Stretching Porous Sheet with Partial Slip, Sci. Res. Engineering, 3(2011), 285-291.

\title{
Влияние поперечного магнитного поля на тепловое излучение непереносимого вынужденного конвекционного потока
}

\author{
Нилангшу Ачария \\ П.Р. Такур Говт Колледж \\ Гаигата, 743287 \\ Индия \\ Субрата Джана \\ Прафуланагар Видиамандер (Х.С.) \\ Хабра, 743268 \\ Индия \\ Калидас Дас \\ А.Б.Н. Сил Коледж \\ Куч Бехар, 736101 \\ Индия
}

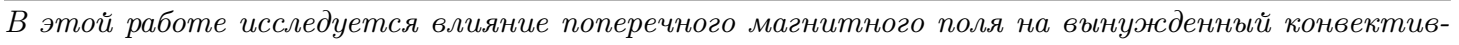
ный поток и теплопередачу несжимаемой электропроводлщей жидкости через полубесконечную пористую пластину, встроенную в пористую среду Дарси-Форххаймера. Тепловое излучение и вязкая диссипация рассматриваются в уравнении энергии. Полученная математическая модель дифференциальных уравнений преобразуется в набор связанных нелинейных обыкновенных дифберенциальных уравнений с исполъзованием преобразований подобия, а затем решается численно с использованием РК-метода четвертого порядка со стрелъбой. Вычислены локальный коэффициент трения кожи и число Нуссельта, представлены графические результаты для безразмерного поля скорости и температуры для некоторых соответствующих параметров, показывающих взаимодействующие аспекты полученного решения.
\end{abstract}

Ключевые слова: вынужденный конвективный поток, пористая среда, тепловое излучение, магнитное поле, вязкая диссипация. 